\title{
A REPORT ON THE STATE OF MOBILE TECHNOLOGIES WITHIN ORGANIZATIONS
}

\author{
Jeretta Horn Nord, Oklahoma State University, jeretta.nord@okstate.edu \\ Alex Koohang, Middle Georgia State University, alex.koohang@mga.edu \\ Joanna Paliszkiewicz, Warsaw University of Life Sciences, joanna_paliszkiewicz@sggw.pl
}

\begin{abstract}
This paper reports on the state of mobile technologies within organizations. A survey consisting of six parts were administered to 181 subjects from various organizations in the USA, India, China, UK, Mexico, and the Netherlands. The survey was conducted between September 2014 and December 2015. In addition to demographics questions, the survey included 21 questions about various aspects of mobile technologies. Collected data were analyzed via frequency distribution. Results are presented in tables and responses are arranged from high to low. Perhaps, the most interesting results are the dominance of Apple iPhones and Samsung Galaxy smart phones and tablets used by employees to support business activities within the organizations. LinkedIn, Facebook, Twitter, YouTube, and Google+ respectively were the most popular types of social media platforms used within organizations. Conclusions and recommendations are made based on the results.
\end{abstract}

Keywords: Mobile Technologies, Mobile Devices, Mobile Apps, Mobile Computing

\section{INTRODUCTION}

Mobile technologies offer connectivity, flexibility, interactivity, and location awareness. It helps organizations' efficiency and the success of business processes (Barnes, 2003). There are many definitions of mobile technologies. Mobile devices, mobile computing, mobile apps, etc. are often used interchangeably to define mobile technologies. For the purpose of this paper, we define mobile technologies as portable technologies that use wireless networks to perform various tasks via mobile devices such as laptops, tablets, netbooks, smart phones, and global positioning systems (GPS). The transmission media used in mobile technologies for transferring data in various forms may include radio wave, microwave, Bluetooth, infrared, or GPS. Mobile devices use various operating systems. An operating system is a component of the system software for managing hardware and software. Mobile apps, a component of mobile technologies, are software applications that are designed specifically for smartphones and tablets.

In recent years, researchers have focused on the adoption, implementation, and use of mobile technologies in organizations (Kim \& Han, 2009; Baran 2014; Karanasios \& Allen, 2014). Mobile devices allow users access to wireless services and applications. The use of mobile devices has become exceptionally popular among people because of their affordability (Newhouse, Williams, \& Pearson, 2006), their ease of transportability, and their availability, always being carried by users (Mattila, 2003). Mobile devices have enabled the increased engagement of workers within organizations. They have signaled new and innovative ways of doing business (Tsang et al., 2004; Liang, et al., 2007; Ko, Jeng 2015).

The rapid development and use of mobile technologies have shown great potential for enhanced communication within organizations (Ko \& Jeng 2015). Examples of mobile devices include laptops, tablets, netbooks, smart phones, and global positioning system (GPS) devices. These devices enable people to use a variety of communication technologies, including Wi-Fi, Bluetooth, 3G, 4G, GSM, GPRS. Mobile devices facilitate communication, Internet access, and data exchange. In business settings, they improve real-time communication. They enhance efficiency and provide new opportunities for organizational activities through collaboration (Shankar \& O’Driscoll, 2002; Rangone \& Renga, 2006).

Mobile applications, also known as apps, are application software programs that are written to run on mobile devices. According to Nah, et al., (2005) there are three advantages of using mobile applications. They provide 


\section{Issues in Information Systems \\ Volume 17, Issue I, pp. 70-79, 2016}

mobility (allowing users to conduct business matters anytime, anywhere), flexibility (allowing users to capture data at the source, or point of origin), and dissemination (allowing users to share real-time information with a larger user population). Ideal mobile applications must embrace functionality, effective user interface, and adaptability. They should be designed to satisfy users (Tarasewich, 2003, Lee \& Benbasat 2004, Lee \& Shim 2006).

The user interface characteristics of mobile devices and / or mobile apps such as portability, performance / operation, usability, and network connectivity have been documented in the literature. (Gebauer et al., 2008; Gebauer \& Ginsburg, 2009). Portability refers to the ability of an app, for example, to run on various mobile devices. Performance / operation refers to speed, battery life, and compatibility of a mobile device. Usability of a mobile device or mobile app refers to the ease of use and comfort. Network connectivity is the strength of the Internet access.

Mobile technologies are often a part of the information systems infrastructure within organizations. They allow users to share information, communicate, and use various business applications anytime, anywhere. Mobile technologies result in efficiency and productivity as users can make better use of their time (Sarker and Wells, 2003; Jarvenpaa et al., 2003).

Quite often mobile devices are used by people to look for common information that might make everyday life easier (Oulasvirta et al., 2012; Ghose et al., 2013). Mobile technologies have been shown to support flexibility of employees (Middleton \& Cukier, 2006). They allow employees to form and participate in various communities of practice (Kietzmann et al., 2013). Mobile technologies enable access to social media platforms, which consists of Internet-based applications allowing the creation and exchange of user-generated content such as videos, music, text, and photos. The most popular social media sites according to a global ranking "The top 500 sites on the web" (Alexa, 2015) are Facebook, LinkedIn, YouTube, Instagram, Pinterest, Blogger, Twitter, and Wikipedia. Social media enables people to be part of a community that shares ideas and information. These platforms are easy to use and enable real-time updates, rapid distribution, and instant feedback. Organizations use them to inform customers about their products and services, campaigns and promotions.

There are, however, drawbacks that face the use of mobile technologies and apps within organizations. Some disadvantages are related to the cost of setting up the equipment and training required to make use of mobile devices. Furthermore, mobile technologies can expose valuable data to unauthorized people, when they are not secured. Loss and theft are perhaps the highest risks with mobile devices because they may contain sensitive and confidential information (Friedman \& Hoffman 2008). Other threats to mobile devices are viruses, worms, trojan horse, and spyware (Madan, Muppidi, Patel, Buecker 2013).

The primary purpose of this paper is to report on the state of mobile technologies within organizations. We collected data from subjects within various organizations in the USA and several other countries. Specifically, the report includes the analysis of collected data regarding the percentage of time employees spend in a day using mobile technologies to conduct business, the ownership of the mobile devices, and the percentage of the use of mobile devices to establish remote connections to back-office systems. Furthermore, we report on the type of mobile devices used within organizations, various mobile apps used to support business within organizations, social media platforms used through mobile devices to support business, and the security of mobile technologies. Finally, we report on the positive and negative experiences attributed to using mobile technologies for business support.

\section{METHOD}

\section{The Survey}

A survey consisting of a number of questions was sent electronically to 181 subjects requesting information about the state of mobile technologies within organizations. The survey consisted of six parts. Part 1 gathered information about 1) the percentage of time, on average, employees spend in a day using mobile technologies to conduct business, 2) the ownership of the mobile devices (individual, company, or both) used to conduct business, and 3) the percentage of the use of mobile devices to establish remote connections to back-office systems. Part 2 


\section{Issues in Information Systems \\ Volume 17, Issue I, pp. 70-79, 2016}

gathered information about the types of mobile devices used within organizations. Part 3 collected information about various mobile apps used to support business within organizations. Part 4 collected information about social media platforms used through mobile devices to support business. Part 5 gathered information about the security measures that organizations provide to secure mobile devices. Part 6 collected information about positive and negative experiences attributed to using mobile technologies for business support.

\section{Subjects \& Procedure}

A majority of the subjects (69\%) were from organizations in various parts of the USA (Northeast: $9 \%$ Midwest: 49\%, South: 6\%, and West: 5\%). The rest of the subjects (31\%) were from organizations in India, China, UK, Mexico, and the Netherlands. The subjects' organizations include sole proprietorship: $12 \%$, partnership: $8 \%$, corporation: $54 \%$, non-profit: $7 \%$, and franchise, cooperative, \& government: $18 \%$. The number of employees in these organizations were 0-250: 34\%, 251-500: 8\%, 501-750: $2 \%, 751-1000: 6 \%$, greater than 1000: 39\%, and not specified: $10 \%$. The organizations' activities included health, manufacturing, retail, service, marketing, sales, energy, \& technology. The data were collected between September 2014 and December 2015.

\section{Analysis}

Collected data were analyzed through frequency distribution. Frequency distribution groups the data into classes. Data are then organized to illustrate how many data points fall into each class. Finally, the numbers are converted to percentages to provide a more informative description of the data.

\section{RESULTS}

Part 1: Time spent using mobile technologies, mobile devices ownership, \& establishing remote connections

1) The percentage of time, on average, employees spend in a day using mobile technologies to conduct business. Only $12 \%$ indicated a great deal of time is spent using mobile technologies to conduct business, followed by $19 \%$ : often, $28 \%$ : occasionally, and $40 \%$ : seldom. (See Table 1)

2) The ownership of the mobile devices - whose mobile devices employees use to conduct business. Of the total responses, $45 \%$ indicated that they use both company owned mobile devices and personal mobile devices to conduct business; $29 \%$ indicated that they use their own mobile devices for company business because mobile devices are not provided by the company; and $25 \%$ indicated that they use the mobile devices provided by the company to conduct business because they are not allowed to use personal devices for business. (See Table 2)

3) Using mobile devices to establish remote connections to back-office systems. Of the total responses to this question, 38\% indicated that they use mobile devices to establish remote connections to back-office systems and $36 \%$ indicated that they did not use mobile devices to establish remote connections to back-office systems. (See Table 3)

\begin{tabular}{|c|c|c|c|c|c|c|c|c|}
\hline \multicolumn{3}{|c|}{ Table 1: Time spend using MT } & \multicolumn{3}{|c|}{ Table 2: Providing mobile devices } & \multicolumn{3}{|c|}{ Table 3: Remote connections } \\
\hline & $f$ & $\%$ & & $f$ & $\%$ & & $f$ & $\%$ \\
\hline Seldom & 73 & $40 \%$ & Both & 82 & $45 \%$ & Yes & 69 & $38 \%$ \\
\hline Occasionally & 51 & $28 \%$ & Employees use own & 53 & $29 \%$ & No & 65 & $36 \%$ \\
\hline Often & 35 & $19 \%$ & Company provides & 46 & $25 \%$ & & 134 & $100 \%$ \\
\hline \multirow[t]{2}{*}{ A great deal } & 22 & $12 \%$ & & 181 & $100 \%$ & \multicolumn{3}{|c|}{ 134/181 responded } \\
\hline & 181 & $100 \%$ & \multicolumn{3}{|l|}{ 181/181 responded } & & & \\
\hline \multicolumn{3}{|c|}{ 181/181 responded } & & & & & & \\
\hline
\end{tabular}




\section{Part 2: Type of mobile devices used within organizations}

The second part of the survey requested information about the type of mobile devices (smart phones, tablets, notebooks, \& laptops) employees use to support business within the organization.

Smart phones: Apple iPhones were the most used smart phones by employees to support business activities within the organizations (40\%), followed by Samsung Galaxy (18\%). Other types of smart phones were used anywhere from $9 \%$ to $4 \%$. (See Table 4 )

Tablets: Apple iPad Air and Apple iPad mini were the leading tablets used by employees to support business activities within the organizations (65\% combined), followed by Samsung Galaxy Note 10.1" (14\%). The use of other types of tablets was from $7 \%$ to $2 \%$. (See Table 5)

Netbook: Over $60 \%$ indicated that they do not use Netbooks to support business activities within the organizations. Only 16\% used Lenovo ThinkPad X120e. The use of other types of Netbooks was from 6\% to 4\%. (See Table 6)

Laptops: Dell laptops were among the highest used by employees to support business activities within the organizations (39\%), followed by Apple (24\%), HP and Lenova (16\% each), Toshiba (4\%), and Acer (1\%). (See Table 7)

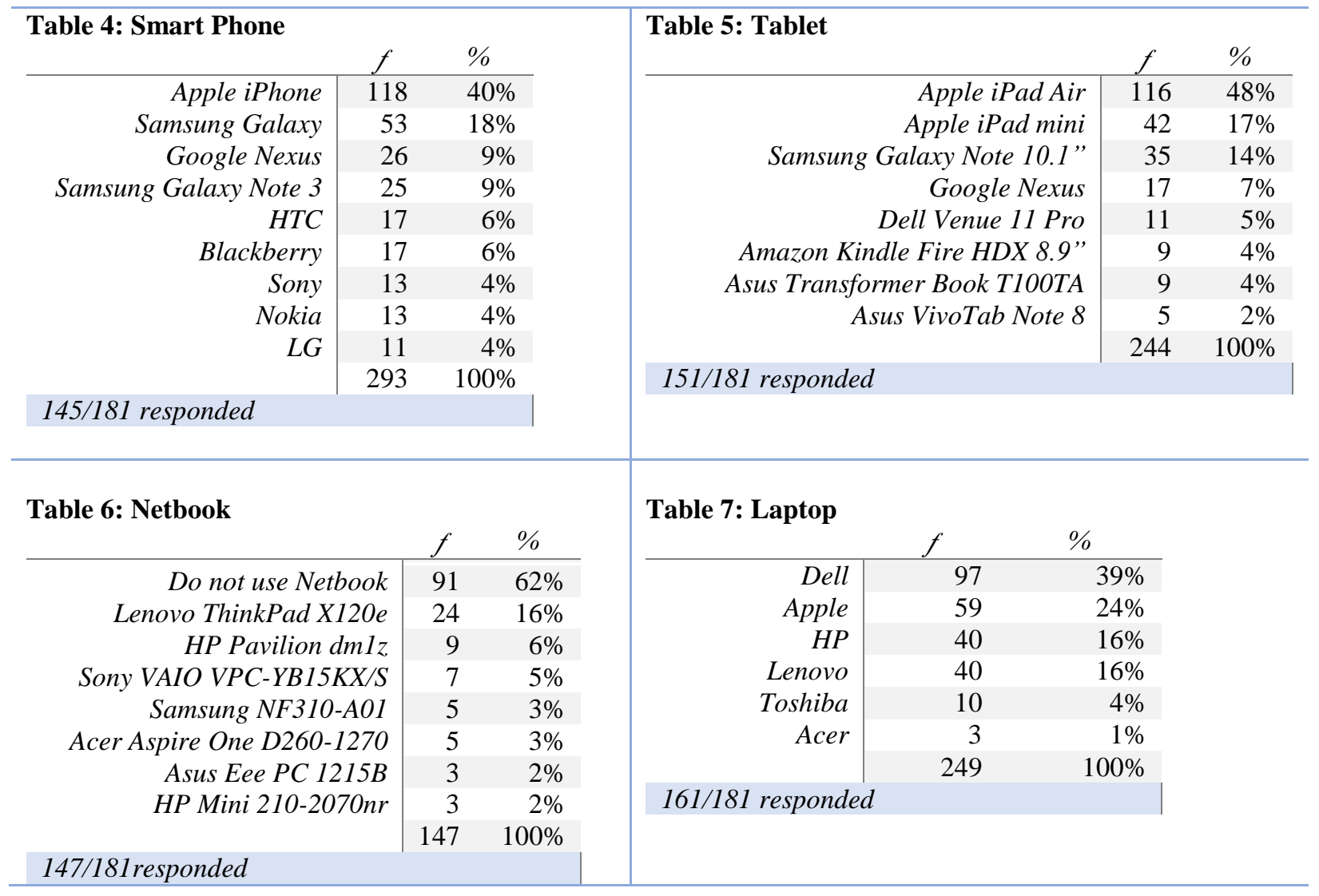




\section{Part 3: Various mobile apps used to support business within organizations}

The third part of the survey requested information about the various mobile apps organizations use to support business within the organization. Specifically, the following information requested:

Business productivity apps to work faster, better, smarter: The most used business productivity app was Audio monos (44\%), followed by CloudOn (18\%), Dropbox for Teams (17\%), and Evernote (13\%). (See Table 8)

Business social networking apps to stay connected to co-workers and customers: LinkedIn (38\%) was the most used business social networking app, followed by Bizzabo (22\%), Hootsuite (17\%), and Tappesty (13\%). (See Table 9)

Business travel/entertainment apps for business trips and meetings: The most used business travel/entertainment apps were AwardWallet (28\%), Uber (23\%), Car Locator (17\%), FlightTrack (13\%). (See Table 10)

\begin{tabular}{|c|c|c|c|c|c|c|c|c|}
\hline \multicolumn{3}{|c|}{ Table 8: Business productivity apps } & \multicolumn{3}{|c|}{$\begin{array}{l}\text { Table 9: Business social } \\
\text { networking apps }\end{array}$} & \multicolumn{3}{|c|}{$\begin{array}{l}\text { Table 10: Business } \\
\text { travel/entertainment apps }\end{array}$} \\
\hline Audio memos & 169 & $44 \%$ & LinkedIn & 91 & $38 \%$ & AwardWallet & 54 & $28 \%$ \\
\hline CloudOn & 70 & $18 \%$ & Bizzabo & 52 & $22 \%$ & Uber & 45 & $23 \%$ \\
\hline Dropbox for Teams & 63 & $17 \%$ & Hootsuite & 40 & $17 \%$ & Car Locator & 33 & $17 \%$ \\
\hline Evernote & 51 & $13 \%$ & Tappesty & 31 & $13 \%$ & FlightTrack & 24 & $13 \%$ \\
\hline LectureNotes & 9 & $2 \%$ & Campfire & 10 & $4 \%$ & OpenTable & 12 & $6 \%$ \\
\hline Workshare & 9 & $2 \%$ & Yammer & 9 & $4 \%$ & StubHub & 9 & $5 \%$ \\
\hline Meeting Mapper & 5 & $1 \%$ & Addappt & 2 & $1 \%$ & Mileage Track & 7 & $4 \%$ \\
\hline Roambi Analytics & 3 & $1 \%$ & CardMunch & 2 & $1 \%$ & TripIt & 7 & $4 \%$ \\
\hline \multirow[t]{2}{*}{ EchoSign } & 2 & $1 \%$ & & 237 & $100 \%$ & HopStop & 1 & $1 \%$ \\
\hline & 381 & $100 \%$ & \multirow{2}{*}{\multicolumn{3}{|c|}{ 140/181 responded }} & & 192 & $100 \%$ \\
\hline 142/181 responded & & & & & & \multicolumn{3}{|c|}{ 102/181 responded } \\
\hline
\end{tabular}

Calendar/To Do apps to keep track of meetings and projects organized: Outlook (78\%), Google Now (18\%) were the most used calendar/to do app. (See Table 11)

Recruiting apps to find employees: For this question, $72 \%$ collectively used the following apps for recruiting: LinkedIn, Beta Alpha Psi, careerbuilder, monster, dice, Naukari.com, Monster.com, Hirevue_Career builder, Recsolu, \& Success Factors. The next most used app was Indeed (24\%). (See Table 12)

Finance/Expenses apps to bill customers and track expenses: For this question, 55\% collectively used the following apps for finance/expenses apps: Concur, iExpense, In house developed invoice system, Onesite, Oracle, OUR 12, Peachtree, Quickbooks Pro, Salesforce ONE, Spectrum, \& Time Ledger. Other most used apps for apps for finance/expenses were Square (18\%), Expensify (14\%), and Time Recording (13\%). (See Table 13)

Communication apps to talk, text, meet, and connect: Blue Jeans Network (36\%) was the most used app for communication. Skype (20\%) was the second most used app for communication, followed by WebEx (14\%). (See Table 14)

Scanning/Printing apps to help with paperwork: The two most scanning/printing apps used within organizations were CamScanner ( $49 \%)$ and ePrint (30\%). (See Table 15) 
Security apps to secure information and keep it in the right hands: In this category, $44 \%$ collectively used the following security apps: iPrism, McAfee, Mobile Iren, netExtender VPN, Norton, Symmatic, Palo Alto Firewalls, Password Keeper, Cisco ASA's at remote sites, Panorama, Bit9, Splunk, and Snort. Box (15\%), Call Blocker (15\%), and My Secret Folder (13\%) were among the other security apps commonly used by organizations. (See Table 16)

\begin{tabular}{|c|c|c|}
\hline \multicolumn{3}{|c|}{ Table 11: Calendar/To Do apps } \\
\hline & $f$ & $\%$ \\
\hline Outlook & 113 & $78 \%$ \\
\hline Google Now & 26 & $18 \%$ \\
\hline Asana & 2 & $1 \%$ \\
\hline Checkmark & 2 & $1 \%$ \\
\hline \multirow[t]{2}{*}{ Clear } & 1 & $1 \%$ \\
\hline & 144 & $100 \%$ \\
\hline
\end{tabular}

Table 12: Recruiting apps

\begin{tabular}{r|rr}
\multicolumn{1}{c}{} & \multicolumn{1}{c}{$\%$} \\
\hline Other & 70 & $72 \%$ \\
Indeed & 23 & $24 \%$ \\
TheLadders & 4 & $4 \%$ \\
& 97 & $100 \%$
\end{tabular}

88/181 responded

132/181 responded

Other - Recruiting apps: LinkedIn, Beta Alpha Psi, careerbuilder, monster,dice, Naukari.com, Monster.com, Hirevue_Career builder, Recsolu, \& Success Factors. Other - Finance/Expenses apps: Concur, iExpense, In house developed invoice system, Onesite, Oracle, OUR 12, Peachtree, Quickbooks Pro, Salesforce ONE, Spectrum, \& Time Ledger

\begin{tabular}{|c|c|c|c|c|c|c|c|c|}
\hline \multicolumn{3}{|c|}{ Table 14: Communication apps } & \multicolumn{3}{|c|}{$\begin{array}{l}\text { Table 15: Scanning/Printing } \\
\text { apps }\end{array}$} & \multicolumn{3}{|c|}{ Table 16: Security apps } \\
\hline Blue Jeans Network & 142 & $36 \%$ & CamScanner & 45 & $49 \%$ & Other & 30 & $44 \%$ \\
\hline Skype & 77 & $20 \%$ & ePrint & 27 & $30 \%$ & Box & 10 & $15 \%$ \\
\hline WebEx & 55 & $14 \%$ & Unsure & 19 & $21 \%$ & Call Blocker & 10 & $15 \%$ \\
\hline Google Hangouts & 36 & $9 \%$ & & 91 & $100 \%$ & My Secret Folder & 9 & $13 \%$ \\
\hline FoxFi & 33 & $8 \%$ & \multicolumn{3}{|c|}{ 84/181 responded } & Hotspot Shield & 4 & $6 \%$ \\
\hline Rabblebrowser & 32 & $8 \%$ & & & & LastPass & 4 & $6 \%$ \\
\hline LogMeIn & 12 & $3 \%$ & & & & TigerText & 1 & $1 \%$ \\
\hline \multirow[t]{2}{*}{ Wi-Fi Finder } & 4 & $1 \%$ & & & & & 68 & $100 \%$ \\
\hline & 391 & $100 \%$ & & & & \multicolumn{3}{|l|}{ 58/181 responded } \\
\hline 170/181 responded & & & & & & & & \\
\hline
\end{tabular}

Other - Security apps: iPrism, McAfee, Mobile Iren, netExtender VPN, Nortem, Symmatic, Palo Alto Firewalls, Password Keeper, Cisco ASA's at remote sites, Panorama, Bit9, Splunk, and Snort.

\section{Part 4: Social media platforms used through mobile devices to support business}

The fourth part of the survey requested information about the types of social media platforms employees use through mobile devices to support business. The types of social media platforms employees use through mobile devices to support business were LinkedIn (24\%), Facebook (22\%), Twitter (17\%), YouTube (12\%), and Google+ (11\%). A number of employees (14\%) indicated that their organization does not allow access to any types of social media platforms used through mobile devices to support business. (See Table 17) 


\begin{tabular}{r|rr}
\hline \multicolumn{3}{c}{ Table 17: SM accessed via MT } \\
& \multicolumn{2}{c}{$\%$} \\
\hline LinkedIn & 95 & $24 \%$ \\
facebook & 86 & $22 \%$ \\
Twitter & 66 & $17 \%$ \\
No SM Access allowed & 53 & $14 \%$ \\
YouTube & 48 & $12 \%$ \\
Google+ & 44 & $11 \%$ \\
& 392 & $100 \%$ \\
176/181 responded & & \\
\hline
\end{tabular}

\section{Part 5: Security measures provided for mobile devices}

The fifth part of the survey requested information about mobile device security. Specifically, the deployment of Mobile Device Management (MDM) software that secures, monitors, manages and supports mobile devices within the organization and the security measures that are enforced on mobile devices.

As shown in Table 18, $40 \%$ of respondents indicated their organizations do not deploy mobile device management to secure, monitor, manage and support mobile devices. For this question, 24\% collectively deploy the following MDM software: 2x MDM, Absolute Software, ActiveClient/ECHELON/DISA, ADP Software security, AirWatch, Citrix, Microsoft Intunel, Sophas, Spiceworks, VPN, and Watchpoint. McAfee - Trust Digital (24\%) and mobile Iron $(11 \%)$ were among other MDM software used by organizations. (See Table 18)

Regarding security measures that are enforced on mobile devices by organizations are PIN code lock (34\%), acceptable use policies (23\%), policies - what data is stored (17\%), ability to remotely delete data (14\%), policies how much data is stored (7\%), and biometrics (5\%). (See Table 19)

\begin{tabular}{|c|c|c|c|c|c|}
\hline \multicolumn{3}{|l|}{ Table 18 : Mobile Device Management } & \multicolumn{3}{|l|}{ Table 19: Security measures MT } \\
\hline \multirow{2}{*}{ My company does not deploy MDM } & $f$ & \multirow{2}{*}{$\begin{array}{l}\% \\
40 \%\end{array}$} & \multirow{2}{*}{\multicolumn{2}{|c|}{$f$}} & \multirow[t]{2}{*}{$\%$} \\
\hline & 57 & & & 138 & \\
\hline Other & 34 & $24 \%$ & Acceptable use policies & 95 & $23 \%$ \\
\hline McAfee (Trust Digital) & 17 & $12 \%$ & Policies - what data stored & 70 & $17 \%$ \\
\hline Mobile Iron & 15 & $11 \%$ & Ability to remotely delete data & 58 & $14 \%$ \\
\hline$R I M$ & 6 & $4 \%$ & Policies - how much data stored & 30 & $7 \%$ \\
\hline SAP/Sybase (Afaria) & 6 & $4 \%$ & Biometrics & 19 & $5 \%$ \\
\hline Good Technologies & 5 & $4 \%$ & & 410 & $100 \%$ \\
\hline BoxTone & 1 & $1 \%$ & 176/181 responded & & \\
\hline & 141 & $100 \%$ & & & \\
\hline 151/181 responded & & & & & \\
\hline
\end{tabular}

Other-MDS: 2x MDM, Absolute Software, ActiveClient/ECHELON/DISA, ADP Software security, AirWatch, Citrix, Microsoft Intunel, Sophas, Spiceworks, VPN, and Watchpoint

\section{Part 6: Positive and negative experiences attributed to using mobile technologies for business support}

The sixth part of the survey requested information about the positive and negative experiences attributed to using mobile technologies for business support. The positive attributes were increased productivity (21\%), better customer support (19\%), improved access to business information (18\%), more timely results (18\%), happier employees (15\%), and increased levels of revenue/profit (10\%). (See Table 20)

The negative attributes were unauthorized access (29\%), loss of governance/control (27\%), less control over employees (26\%), higher levels of loss/theft (15\%), and decline in revenues/profits (3\%). (See Table 21) 


\begin{tabular}{|c|c|c|c|c|c|}
\hline \multicolumn{3}{|l|}{ Table 20: Positive attributes } & \multicolumn{3}{|l|}{ Table 21: Negative attributes } \\
\hline & $f$ & $\%$ & & $f$ & $\%$ \\
\hline Increased productivity & 131 & $21 \%$ & Unauthorized access & 38 & $29 \%$ \\
\hline Better customer support & 118 & $19 \%$ & Loss of governance/control & 35 & $27 \%$ \\
\hline Improved access to business information & 112 & $18 \%$ & Less control over employees & 33 & $26 \%$ \\
\hline More timely results & 111 & $18 \%$ & Higher levels of loss/theft & 19 & $15 \%$ \\
\hline Happier employees & 95 & $15 \%$ & Decline in revenues and profits & 4 & $3 \%$ \\
\hline \multirow[t]{2}{*}{ Increased levels of revenue and profit } & 60 & $10 \%$ & & 129 & $100 \%$ \\
\hline & 627 & $100 \%$ & 129/181 responded & & \\
\hline 178/181 responded & & & & & \\
\hline
\end{tabular}

\section{CONCLUSIONS}

This paper reported on a six-part survey on the state of mobile technologies conducted between September 2014 and December 2015 in various organizations in the USA, India, China, UK, Mexico, and the Netherlands. The survey results are depicted in tables with responses presented from high to low. Several interesting and important highlights of the report are as follows:

- Only $12 \%$ of respondents indicated "a great deal" of time spent using mobile technologies to conduct business, followed by $19 \%$ of the respondents indicating "often" using mobile technologies to conduct business. The majority (68\%) either use mobile technologies "occasionally" or "seldom". Although the use of mobile technologies continues to grow, these results clearly indicate that the use of mobile technologies to conduct business activities is still not in full swing within organizations.

- Though $25 \%$ of companies provide mobile devices to employees to conduct business activities, $29 \%$ of employees use their own mobile devices to conduct business activities. A large percentage of employees use a combination of personal and company owned mobile technologies to conduct business activities $(45 \%)$.

- Apple iPhones were the most used smart phones by employees to support business activities within the organizations (40\%) followed by Samsung Galaxy smart phones (18\%).

- The tablets used by organizations to conduct business activities is dominated by Apple iPad Air and Apple iPad mini (65\% combined), followed by Samsung Galaxy Note 10.1” (14\%).

- Various Apps are being used with mobile devices to conduct business activities.

- LinkedIn, Facebook, Twitter, YouTube, and Google+ respectively were the most popular types of social media platforms employees use through mobile devices to support business.

- As for mobile technologies security, $40 \%$ of the respondents indicated that their organizations do not deploy mobile device management to secure, monitor, manage and support mobile devices. This is alarming as the security of mobile technologies should be considered of utmost importance to the existence of an organization.

- The positive attributes of mobile technologies used in organizations to conduct business activities were increased productivity, better customer support, improved access to business information, more timely results, happier employees, and increased levels of revenue/profit respectively.

- The negative attributes of mobile technologies used in organizations to conduct business activities were unauthorized access, loss of governance/control, less control over employees, higher levels of loss/theft, and decline in revenues/profits respectively.

Though apps are widely used with mobile devices to conduct business activities, a report by Morgan Stanley (2015) showed that mobile browser viewers are twice as large as app viewers, and they tend to grow more rapidly. If this trend is advancing at a rapid pace, then mobile browsers should be designed with sound usability and user interfaces to make it easier to conduct business activities. 


\section{Issues in Information Systems}

Volume 17, Issue I, pp. 70-79, 2016

Mobile technologies are rapidly taking over the traditional way of day-to-day computing, conversing, purchasing, and conducting business. Now, the focus should turn to the future of mobile technologies with attention to enterprise mobile management, wearable mobile devices, $5 \mathrm{G}$ networks, and multiplatform mobile development tools.

\section{REFERENCES}

Alexa (2015). The top 500 sites on the web. Available at www.alexa.com Accessed 12 Aug 2015.

Baran, E. (2014). A Review of Research on Mobile Learning in Teacher Education. Educational Technology \& Society, 17 (4), 17-32.

Barnes, S. (2003). Wireless applications in the firm's value chain. M-business: the strategic implications of wireless communications, Butterworth-Heinemann, MA, 38-59.

Friedman, J., \& Hoffman, D. (2008). Protecting data on mobile devices: A taxonomy of security threats to mobile computing and review of applicable defenses. Information Knowledge Systems Management, 7(1, 2), 159180.

Gebauer, J. (2008). User Requirements of Mobile Technology: A summary of research results. Information Knowledge Systems Management, 7, 101-119.

Gebauer, J., \& Ginsburg, M. (2009). Exploring the Black Box of Tasktechnology Fit: The case of mobile information systems. Communications of the ACM, 52(1): 130-135.

Ghose, A., Goldfarb, A., \& Han, S. (2013). How is the mobile internet different? Search costs and local activities. Information Systems Research, 24(3), 613-631.

Jarvenpaa, S., Lang, K., Takeda, Y., \& Tuunainen, V. (2003). Mobile commerce at crossroads. Communications of the ACM, 46(12), 41-44.

Karanasios S., Allen D., (2014). Mobile technology in mobile work: contradictions and congruencies in activity systems. European Journal of Information Systems, 23, 529-542.

Kietzmann, J., Plangger, K., Eaton, B., Heilgenberg, K., Pitt, L. \& Berthon, P. (2013). Mobility at work: a typology of mobile communities of practice and contextual ambidexterity. Journal of Strategic Information Systems, 22(4), 282-297.

Kim, B., \& Han, I. (2009). What drives the adoption of mobile data services an approach from a value perspective. Journal of Information Technology, 24(1), 35-45.

Ko, Ch. H., \& Jeng S., (2015). Mobile Technology Adopted in Hotel Sales. The International Journal of Organizational Innovation, 8(2), 172-186.

Lee, C., \& Shim, J. (2006). An Empirical Study on User Satisfaction with Mobile Business Applications Use and Hedonism. Journal of Information Technology Theory and Application, 8(3), 57-74.

Lee, Y., \& Benbasat, I. (2004). A Framework for the Study of Customer Interface Design for Mobile Commerce, International Journal of Electronic Commerce, 8(3), 79-102.

Liang, T., Huang Ch. W., Yeh Y., \& Lin, B. (2007). Adoption of mobile technology in business: a fit-viability model. Industrial Management \& Data Systems, 10 (8), 1154-1169.

Madan, A., Muppidi, S., Patel, N., \& Buecker, A. (2013). Securely Adopting Mobile Technology Innovations for Your Enterprise Using IBM Security Solutions. Redguide for Business Leaders, IBM Corp, 1-42. 


\section{Issues in Information Systems}

Volume 17, Issue I, pp. 70-79, 2016

Mattila, M. (2003). Factors affecting the adoption of mobile banking services. Journal of Internet Banking and Commerce, 8(1), 0306-04.

Middleton, C., \& Cukier, W. (2006). Is mobile email functional or dysfunctional? Two perspectives on mobile email usage. European Journal of Information Systems, 15(3), 252-260.

Morgan Stanley (2015). No, Apps Aren't Winning. The Mobile Browser Is. Retrieved February 20, 2016 form http://marketingland.com/morgan-stanley-no-apps-arent-winning-the-mobile-browser-is-144303

Nah, F., Siau, K., \& Sheng, H. (2005). The value of mobile applications: a utility company study. Communications of the ACM, 48(2), 85-90.

Newhouse, C. P., Williams, P. J., \& Pearson, J. (2006). Supporting Mobile Education for Pre-Service Teachers. Australasian Journal of Educational Technology, 22(3), 289-311.

Oulasvirta, A., Rattenbury, T., Ma, L., \& Raita, E. (2012). Habits make smartphone use more pervasive. Personal and Ubiquitous Computing, 16(1), 105-114.

Rangone, A., \& Renga, F. M. (2006). B2e mobile internet: an exploratory study of Italian applications. Business Process Management Journal, 12(3), 330-343.

Sarker, S. \& Wells, J.D. (2003). Understanding mobile handheld device use and adoption. Communications of the ACM, 46(12), 35-40.

Shankar, V., \& O’Driscoll, T. (2002). How wireless networks are reshaping the supply chain. Supply Chain Management Review, 6(4), 44-51.

Tarasewich, P. (2003). Designing Mobile Commerce Applications. Communications of the ACM, 46(12), 57-60.

Tsang, M. M., Ho, S. C., \& Liang, T. P. (2004). Consumer attitudes toward mobile advertising: An empirical study. International journal of electronic commerce, 8(3), 65-78. 